\title{
Global Innovations Symposium Flies High at TMS 2010
}

\section{Lynne Robinson}

Editor's Note: This is excerpted from an article that first appeared on MaterialsTechnology@TMS and is now archived in the Emerging Materials Community at http://materialstechnology.tms.org /EMT/home.aspx.

Floating on muslin wings and bound together with horsehide glue, the Wright Flyer launched powered air travel in four shuddering flights of less than a minute each in 1903. Its fragile wooden frame, ultimately reduced to splinters by a heavy gust of wind, stood in stark contrast to the powerful aircraft that now routinely soar above the clouds. What these two eras of flight have very much in common, however, is a drive for discovery and innovation. This pursuit of new technology to enable faster, safer, and more cost-efficient flight will be explored and celebrated during the TMS 2010 Annual Meeting at the 11th Materials Processing \& Manufacturing Division (MPMD) Global Innovations Symposium: Global Innovations in Manufacturing of Aerospace Materials.

Chosen, in part, for the meeting's location in the aerospace center of Seattle, the symposium's topic will highlight key advances in the manufacturing of aerospace materials across a wide spectrum of technologies. Said Deborah D. Whitis, section manager,

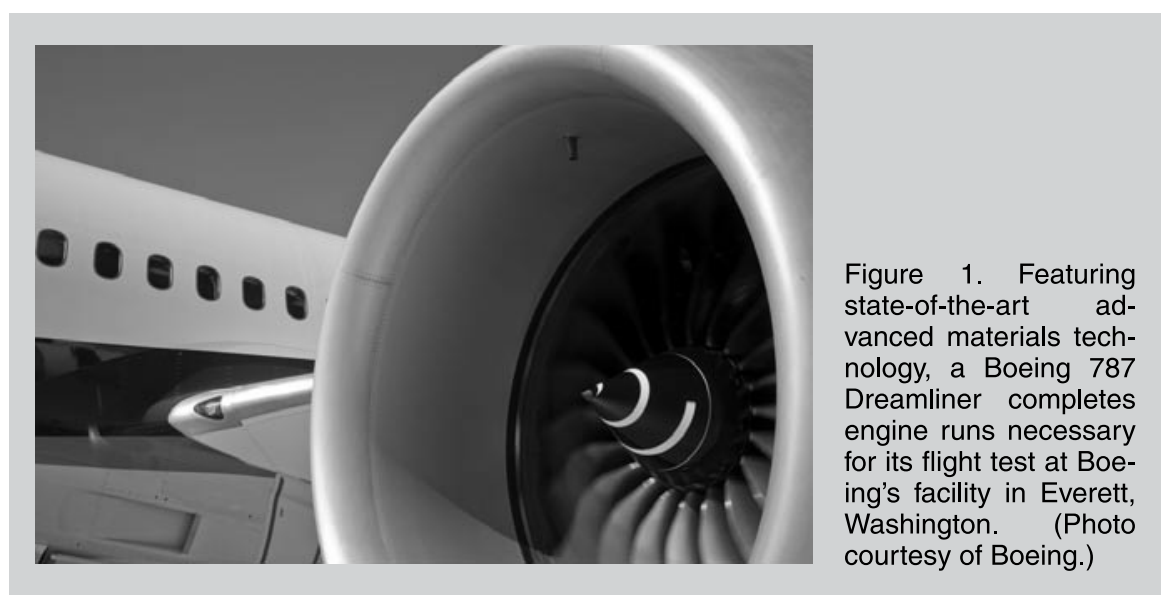

Materials Applications Engineering for GE Aviation and symposium organizer, "The symposium has been split into several sessions to highlight different trends across various manufacturing processes such as casting, forming/forging, and machining/joining, as well as alloy systems, including titanium, superalloys, and intermetallics. One exciting trend to be examined will be additive manufacturing, which has recently seen a resurgence due to advances in powder manufacturing methods."

Computational materials engineering will also be highlighted, because, said Whitis, "An overarching challenge and opportunity for our community is to better incorporate modeling and simulation into metals processing in order to develop new alloys and processes more quickly and with fewer iterations."

According to Whitis, this year's symposium provides a balanced perspective with a number of invited speakers from industry, academia, and government. Kicking off the symposium on February 15 will be "Future Materials and Process Needs for Commercial Jet Transports: the 21st Century Challenge," a keynote presentation by Alan Miller, director of 787 Technology Invanced materials technology, a Boeing 787 Dreamliner completes gine runs necessary courtesy of Boeing.) Washington. (Photo tegration for Boeing.

As a member of both the MPMD's Shaping and Forming Committee and the Structural Materials Division's (SMD) High Temperature Alloys Committee, Whitis said she was pleased to have been able to integrate the interests and involvement of both groups in developing the symposium. Exchanging knowledge and ideas across disciplines to provide a more comprehensive view of trends and advancements has been the cornerstone of the Global Innovations Symposium since it was introduced a decade ago as a new concept in programming at the TMS Annual Meeting. In addition to organizing their own symposia, the MPMD's technical committees were asked to contribute to a division "super-symposium" that reflected the breadth of materials processing and manufacturing within an emerging technology or industry. "It was our desire to engage as many production organizations as possible to strengthen the technical breadth of our membership - both within the division and within the society," said John Smugeresky, technical staff member at Sandia National Labs and MPMD chair at the time that the symposium was established.

"The Global Innovations Symposium has historically featured high profile speakers to provide a foundation for focused topics where new innovation has been occurring," said Thomas R. Bieler, professor at Michigan State University and symposium co-organizer. "This year's event is no exception and will provide participants the opportunity to gain a high-level view of where the industry is heading in using new technologies to improve production of aerospace materials and parts."

Lynne Robinson is a news and feature writer for TMS. 